\title{
Sprites identification and their spatial distributions in JEM-GLIMS nadir observations
}

\author{
Mitsuteru Sato ${ }^{1, *}$, Toru Adachi ${ }^{2}$, Tomoo Ushio ${ }^{3}$, Takeshi Morimoto ${ }^{4}$, Masayuki Kikuchi ${ }^{5}$, \\ Hiroshi Kikuchi ${ }^{3}$, Makoto Suzuki ${ }^{6}$, Atsushi Yamazaki ${ }^{6}$, Yukihiro Takahashi ${ }^{1}$, Ryohei Ishida ${ }^{7}$, \\ Yuji Sakamoto ${ }^{8}$, Kazuya Yoshida ${ }^{8}$, and Yasuhide Hobara ${ }^{9}$ \\ ${ }^{1}$ Faculty of Science, Hokkaido University, Sapporo, Japan \\ ${ }^{2}$ Meteorological Research Institute, Tsukuba, Japan \\ ${ }^{3}$ Faculty of Engineering, Osaka University, Suita, Japan \\ ${ }^{4}$ Faculty of Science and Engineering, Kindai University, Higashiosaka, Japan \\ ${ }^{5}$ National Institute of Polar Research (NIPR), Tachikawa, Japan \\ ${ }^{6}$ Institute of Space and Astronautical Science (ISAS), JAXA, Sagamihara, Japan \\ ${ }^{7}$ Faculty of Engineering, Osaka Prefecture University, Sakai, Japan \\ ${ }^{8}$ Department of Engineering, Tohoku University, Sendai, Japan \\ ${ }^{9}$ Faculty of Informatics and Engineering, The University of Electro-Communications, Chofu, Japan
}

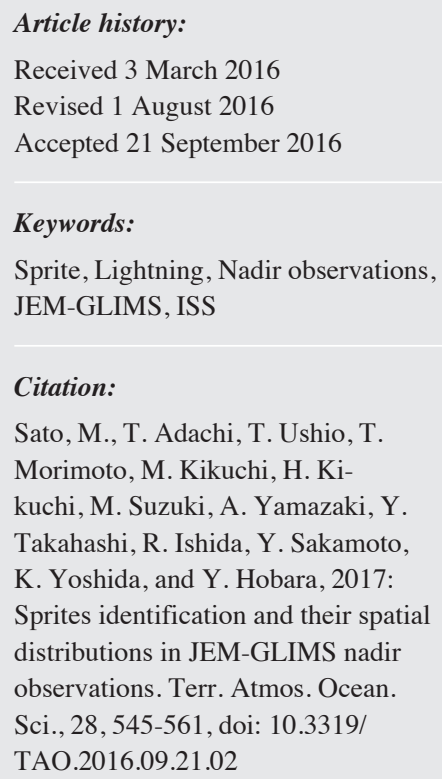

Received 3 March 2016

Revised 1 August 2016

Accepted 21 September 2016

Keywords:

Sprite, Lightning, Nadir observations, JEM-GLIMS, ISS

Citation:

Sato, M., T. Adachi, T. Ushio, T. Morimoto, M. Kikuchi, H. Kikuchi, M. Suzuki, A. Yamazaki, Y. Takahashi, R. Ishida, Y. Sakamoto, K. Yoshida, and Y. Hobara, 2017: Sprites identification and their spatial distributions in JEM-GLIMS nadir observations. Terr. Atmos. Ocean. Sci., 28, 545-561, doi: 10.3319/ TAO.2016.09.21.02

\begin{abstract}
The Global Lightning and Sprite Measurements on the Japanese Experiment Module (JEM-GLIMS) started continuous nadir observations of lightning and transient luminous events (TLEs) at the International Space Station (ISS) in November 2012 and completed the observations in August 2015. As JEM-GLIMS uses the nadir observation technique, the JEM-GLIMS optical instruments simultaneously measure both incomparably intense lightning emissions and weak sprite emissions. We adopted combined data analytical methods to distinguish between these two types of emissions: (1) a subtraction of the wideband LSI-1 image from the narrowband LSI-2 image, (2) a calculation of the intensity ratio between different photometer channels, and (3) an estimation of the charge moment change (CMC) of the suspected sprite-producing CG discharge. This report presents as a case study one sprite event detected at 19:50:40.30580 UT on 28 September 2013 and identified using the above analytical methods. From the results derived from detailed data analyses, we judged that the optical emission measured by LSI-2 is a sprite emission. We carried out the geometry conversion toward the LSI-1 and subtracted images and found that the sprite emission location shifts by $3.5 \mathrm{~km}$ from the peak lightning emission location, which agree with the previous reports. The detailed horizontal distributions of sprites and the relationship between the sprite location and the parent lightning location are quantitatively revealed for the first time.
\end{abstract}

\section{INTRODUCTION}

Transient optical discharge phenomena occurring above active thunderclouds were discovered in the 1990's. These phenomena are called transient luminous events (TLEs) and are the electrodynamic processes connecting the lower atmosphere to the upper atmosphere. Sprites are one TLE occurrence types, and they have been intensively studied by a number of ground-based optical and electromagnetic obser-

\footnotetext{
* Corresponding author

E-mail:msato@ep.sci.hokudai.ac.jp
}

vations since the discovery (Franz et al. 1990; Sentman et al. 1995; Lyons 1996). These observational studies clarified the occurrence characteristics of sprites: (1) they typically occur in the altitude range of $50-90 \mathrm{~km}$, (2) a time constant of the sprite optical emissions is from a few milliseconds to a few tens of milliseconds, and (3) they are excited by lightning discharges having a charge moment change (CMC) over $600 \mathrm{C} \mathrm{km} \mathrm{(Hu} \mathrm{et} \mathrm{al.} \mathrm{2002;} \mathrm{Moudry} \mathrm{et} \mathrm{al.} \mathrm{2003;} \mathrm{Cum-}$ mer and Lyons 2005). Theoretical studies on the sprite generation mechanisms revealed that sprite optical emissions 
are produced by the excitation/relaxation processes of neutral molecules and ions in the atmosphere, i.e., mainly $\mathrm{N}_{2}$ and $\mathrm{N}_{2}{ }^{+}$(Pasko et al. 1997, 1998; Ebert et al. 2006). These excitation processes are induced by collisions between these particles and the ambient electrons accelerated by the quasielectrostatic (QE) field generated by cloud-to-ground (CG) discharges. In contrast, elves is another TLE occurrence type (Fukunishi et al. 1996). Elves appears at $\sim 90 \mathrm{~km}$ altitude and exhibits a doughnut-like optical shape with the lateral expansion of a few hundred kilometers within $\sim 1 \mathrm{~ms}$ (Inan et al. 1996). The generation mechanism of elves optical emissions is similar to that of sprites. However, the ambient electron acceleration is caused by the radiative electric field from the lightning-producing electromagnetic pulses (EMPs) (Nagano et al. 2003; Marshall et al. 2010).

Studies on the sprite generation mechanisms have thus far shown great progress (Pasko et al. 1997, 1998; Ebert et al. 2006, 2011; Liu and Pasko 2006; Luque et al. 2007; Pasko 2010; Luque and Ebert 2012). However, the physical parameters that determine the horizontal distributions of sprites, i.e., the occurrence conditions, are not fully understood. It has recently been suggested that the inhomogeneity in the electron density at $80-90 \mathrm{~km}$ altitudes may play a crucial role in determining the horizontal distributions of sprites and the formation of sprite streamers (Qin et al. 2012, 2013). There are many factors that can create such inhomogeneity, such as, atmospheric gravity waves, micrometeors and the interference of lightning-producing EMPs (Sato et al. 2015). In order to clarify these factors, the observational identification of the horizontal distributions of sprites has become first important. In general, the feasibility to simultaneously detect the same sprite emissions from multiple observation sites on the ground is quite low due to the geographical and meteorological limitations. Therefore, nadir observations of lightning and sprite emissions from space are essentially important to identifying the horizontal distributions of sprites.

TLE optical observations from space were first conducted in the space shuttle missions in the early 1990's (Boeck et al. 1992, 1995, 1998). As the next generation of space observations, the Imager of Sprites and Upper Atmospheric Lightning (ISUAL) onboard the FORMOSAT-2 satellite started continuous optical observations in 2004 and succeeded in detecting a number of TLEs (Frey et al. 2005; Kuo et al. 2005, 2007; Mende et al. 2005; Adachi et al. 2008; Chang et al. 2010; Takahashi et al. 2010). However, the field of view (FOV) of the ISUAL instruments is directed toward the Earth's limb in order that they can easily and efficiently detect TLEs. Consequently, it is difficult to precisely determine the horizontal distributions of sprites from the ISUAL data. Blanc et al. (2004) first conducted nadir lightning and TLE observations from the International Space Station (ISS) and reported on the detection of possible sprite events. However, the $\pm 1 \mathrm{~s}$ time accuracy of the data prevented them from identifying the suspected parent lightning discharges using the ground-based lightning detection network data. Other TLE observations from the ISS were recently conducted using a high-sensitive electron multiplication CCD camera and commercial-based digital camera, which contributed to detecting distinct TLE color images (Yair et al. 2004, 2013; Jehl et al. 2013). However, these observations were operated under campaign-based missions. Thus, understanding the sprite occurrence conditions did not progress greatly.

The Global Lightning and Sprite Measurements on the Japanese Experiment Module (JEM-GLIMS) is a space mission designed to conduct nadir lightning and TLE observations from the ISS. The main objectives of this mission are (1) to identify the horizontal distributions of sprites and the relation to the parent lightning discharges, and (2) clarify the sprite occurrence condition (Ushio et al. 2011). Using JEM-GLIMS and ground-based lightning data, we expect to identify the electrodynamic coupling processes between lightning discharges and TLEs. In this report, we introduce the detailed methods used to distinguish between weak sprite emissions from the incomparably intense lightning emissions in the nadir observation data and present one sprite event as a case study. In section 2, the JEM-GLIMS instruments and observation method are introduced. In section 3 , the detailed sprite distinction analytical methodologies are described. In section 4 , one sprite event identified using these distinction methods is presented as a case study. The conclusions from this report are given in section 5. In the series of previous papers introducing the JEM-GLIMS results, the methodologies to distinguish sprite emissions from lightning emissions have not been described in detail. The main focus of this report is therefore to present these methodologies, i.e., descriptions in chapter 3 .

\section{JEM-GLIMS NADIR OBSERVATIONS}

\subsection{Science Instruments}

JEM-GLIMS instruments are comprised of four science instruments, one onboard computer and one Global Positioning System (GPS) receiver (Sato et al. 2015). Two of the four science instruments are optical devices, i.e., Lightning and Sprite Imager (LSI) and six-channel Spectrophotometer (PH). The LSI consists of two CMOS cameras whose specification is almost identical except for the passband of the optical filter (Sato et al. 2011a). The wideband camera (LSI-1) and narrowband camera (LSI-2) measure the optical emissions in the $768-830$ and $760-775 \mathrm{~nm}$ wavelength ranges, respectively. Since the FOV of the LSI is $28.3^{\circ} \times 28.3^{\circ}$, the spatial resolution at the ground surface and $80 \mathrm{~km}$ altitude is $400 \mathrm{~m} \times 400 \mathrm{~m}$ and $320 \mathrm{~m} \times 320 \mathrm{~m}$, respectively. The sampling time is $32.8 \mathrm{~ms} \mathrm{frame}^{-1}$, and the image intensity resolution is 10 bit. The $\mathrm{PH}$ consists of sixchannel spectrophotometers, denoted by PH1 - PH6. Each 
$\mathrm{PH}$ channel is equipped with the optical filter whose passband is $\lambda_{\mathrm{PH} 1}=150-280 \mathrm{~nm}, \lambda_{\mathrm{PH} 2}=332-342 \mathrm{~nm}, \lambda_{\mathrm{PH} 3}=$ $755-766 \mathrm{~nm}, \lambda_{\mathrm{PH} 4}=599-900 \mathrm{~nm}, \lambda_{\mathrm{PH} 5}=310-321 \mathrm{~nm}$, and $\lambda_{\mathrm{PH} 6}=386-397 \mathrm{~nm}$ (Sato et al. 2011b). The PH1 $\mathrm{PH} 3, \mathrm{PH} 5$, and PH6 have a conical FOV of $42.7^{\circ}$, which is nearly equal to the circumscribed circle of the LSI FOV, while the PH4 has a conical FOV of $86.8^{\circ}$. The sampling time of the $\mathrm{PH}$ system is $50 \mu \mathrm{s}$, and the digitizing resolution is 12 bit. Besides two optical instruments, JEM-GLIMS is equipped with two types of electromagnetic wave receivers, i.e., VLF Receiver (VLFR) and VHF Interferometer (VITF) (Morimoto et al. 2011). All science instruments are controlled by the onboard computer (SHU: Science Instrument Handling Unit) (Kikuchi et al. 2011). In this report, LSI and PH data are mainly analyzed.

\subsection{Observation and Trigger Sequences}

The JEM-GLIMS lightning and TLE observations are operated when the ISS is located in the Earth's shadow. Since the orbital inclination, typical altitude and period of the ISS are $51^{\circ}, \sim 410 \mathrm{~km}$, and $90 \mathrm{~min}$, respectively, the maximum observation time becomes $\sim 30 \mathrm{~min}_{\text {orbit }}{ }^{-1}$. All of the JEM-GLIMS instruments are installed on the baseplate of the bus system, which is always directed to the nadir. Thus, JEM-GLIMS can conduct nadir observations from the ISS, even though the actual center position of the LSI and PH FOVs is slightly different from the nadir point according to the ISS attitude (Sato et al. 2015).

Due to the limited telemetry rate, JEM-GLIMS uses the event triggering technique. The optical and electromagnetic wave data around the event trigger time are stored. LSI image data are recorded for four consecutive frames from one frame before the trigger time, while $\mathrm{PH}$ light curve data are recorded for $512 \mathrm{~ms}$ time period from $100 \mathrm{~ms}$ before the trigger time. In usual observations, $\mathrm{PH}$ is selected as a trigger instrument. The GPS receiver can provide the precise coordinated universal time (UT) to the JEM-GLIMS system, and the time accuracy is in the order of $\mu \mathrm{s}$. When
PH detects a transient optical emission whose amplitude exceeds the trigger threshold level, the SHU stamps the UT at the trigger time on all JEM-GLIMS data (Sato et al. 2015).

\subsection{Summary of the JEM-GLIMS Observations}

JEM-GLIMS conducted continuous lightning and TLE observations for three years from 20 November 2012 to 24 August 2015. During the nominal operation period from November 2012 to December 2014, JEM-GLIMS did not carry out observations over the South Atlantic Anomaly (SAA) in order to avoid instrument damage caused by a direct hit of high-energy particles. In contrast, JEM-GLIMS carried out observations over the SAA during an extended operating period starting at the end of December 2014.

Figure 1 shows a summary of the events detected by JEM-GLIMS optical instruments for the three-year observation period. JEM-GLIMS succeeded in detecting a total of 8357 lightning events and 699 TLEs. The TLE identification method is presented later in this report. From the detailed comparison between JEM-GLIMS data and groundbased ELF waveform data, 129 events of 699 TLEs were excited by positive CG (+CG) discharges, while 491 events of 699 TLEs were excited by negative CG (-CG) discharges. In 79 of 699 TLEs, no intense transient ELF signals were detected, which implies that these events may be associated with CG discharges exciting only weak ELF signals or with intra-cloud (IC) discharges. 42 and 508 of 699 TLEs are identified as sprites and elves. The occurrence types of 149 TLEs are not yet determined, which will be identified by further detailed data analyses. The detection ratio for the 42 sprite events and 508 elves events of the 8357 total lightning events is 0.5 and $6.1 \%$, respectively.

\section{IDENTIFICATION OF SPRITE EMISSIONS}

JEM-GLIMS simultaneously measures both the incomparably bright lightning emissions and the relatively weak TLE emissions from the ISS. Thus, the spatial and temporal

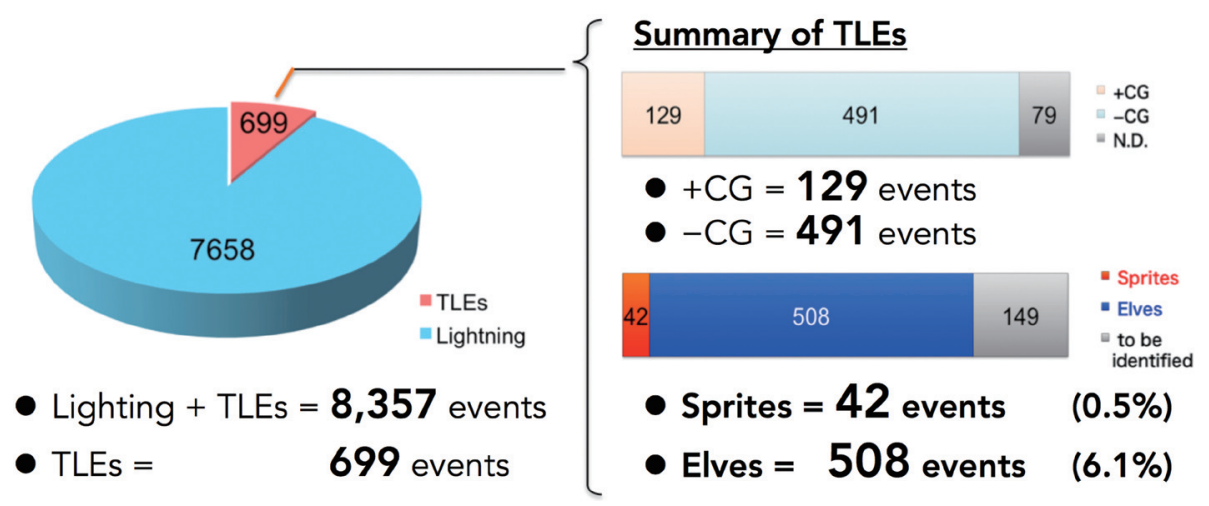

Fig. 1. Summary of the lightning events and TLEs detected by the JEM-GLIMS optical instruments. (Color online only) 
separation between these emissions is generally difficult. We adopted criteria to judge TLE occurrence, which depends on the results derived from the JEM-GLIMS and ground-based ELF measurement data analyses, according to (1) a LSI-1 image subtraction from the LSI-2 image, (2) a calculation of the peak intensity ratio between different $\mathrm{PH}$ channels, and (3) an estimation of CMC for the suspected parent lightning discharges. In the following subsections, these data analysis methods are introduced in detail.

\subsection{Image Subtraction Method for LSI Data}

In the pass band of the LSI-1 filter, there are lightning emissions of OI $(777.4 \mathrm{~nm})$, OI $(794.7 \mathrm{~nm})$, and NI $(820.0 \mathrm{~nm})$ and TLE emissions from $\mathrm{N}_{2} 1 \mathrm{P}_{(2,0)}(775.4 \mathrm{~nm})$ and $\mathrm{N}_{2} 1 \mathrm{P}_{(6.5)}(804.7 \mathrm{~nm})$ (Orville and Henderson 1984; Bucsela et al. 2003; Gordillo-Vázquez et al. 2011). As the typical optical energy of lightning and sprites is $\sim 1 \mathrm{MJ}$ and $\sim 300 \mathrm{~kJ}$, respectively (Takahashi et al. 2010; Quick and Krider 2013), the LSI-1 mainly observes lightning emissions. In contrast, in the pass band of the LSI-2 filter, there are continuum lightning emissions and TLE emissions of $\mathrm{N}_{2}$ $1 \mathrm{P}_{(3,1)}(762.7 \mathrm{~nm})$. However, $\mathrm{O}_{2}$ molecules in the atmosphere absorb the continuum lightning emissions during propagation from the lightning altitude to the ISS. Thus, the LSI-2 measures both TLE emissions and attenuated weak lightning emissions. For this reason, a subtraction of the appropriately scaled LSI-1 image from the LSI-2 image is required to extract only the TLE emissions (Sato et al. 2015). The image subtraction acquired by two cameras having a similar configuration was first proposed by Blanc et al. $(2004,2012)$. We basically used the same subtraction scheme.

As a first step, the dark image subtraction and the flat field correction are performed on LSI-1 and LSI-2 images according to the following equation,

$L S I_{\text {corr }}=\frac{L S I_{o b s}-D K}{\tau}$

where $L S I_{\text {corr }}$ and $L S I_{o b s}$ are the image data that corrected the flat field and dark level and the observed raw image data, respectively. $D K$ and $\tau$ are the dark image data and the flat field image, respectively. We created the dark image data by averaging the 178 LSI images, where there is no lightning emission, taken during the new moon period. This dark image data is compared to that obtained at the calibration experiment before the launch, and we confirmed that the dark noise levels in these two images are identical. Thus, we used the dark image data created from the 178 LSI images. As for the flat field image, we could not obtain suitable images in the orbit and decided to use the flat field image acquired during the calibration experiment on the ground. The relative transmittance of the LSI-1 optics varies from 1.0 at the center of the optical axis to $\sim 0.6$ at the edge of the FOV, while that of the LSI- 2 optics varies from 1.0 to $\sim 0.7$. The difference in the relative transmittance between the LSI-1 and LSI- 2 optics must be originated in the different optical filter characteristics.

As a next step, the LSI-1 image offset toward the LSI-2 image is corrected. This offset originated in the difference in the mechanical alignment between the LSI-1 and LSI-2 CMOS sensors. The LSI observed lightning emissions but also city light emissions. Using these city light images, the offset values are statistically estimated. Figure $2 \mathrm{a}$ is an example of the city light images observed at 02:41:22 UT on 28 January 2014 . The ISS location was $\left(4.82^{\circ} \mathrm{E}, 51.56^{\circ} \mathrm{N}\right)$, and the spot-like emissions in the images correspond to the city lights of Amsterdam, Holland. From these spot-like emissions, the cross correlations $(P)$ are calculated using the following equation,

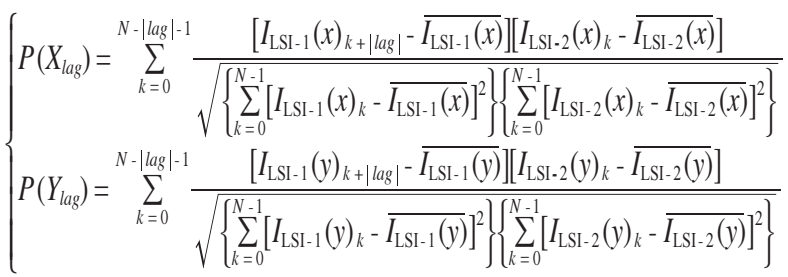

where $X_{l a g}$ and $Y_{\text {lag }}$ are the lag values (i.e., offset values) in the $\mathrm{X}$ - and Y-pixel directions of the image, respectively. $I_{\mathrm{LSI}-1}(x)$ and $I_{\mathrm{LSS}-1}(y)$ are the intensity profile of the city light emissions in the LSI-1 image $\left[I_{\mathrm{LSI}-1}(x, y)\right]$ and LSI-2 image $\left[I_{\mathrm{LSI}-2}(x, y)\right]$. These intensity profiles are calculated by integrating the city light image along the $\mathrm{X}$ - and $\mathrm{Y}$-pixel directions, that is,

$\left\{\begin{array}{l}I_{\mathrm{LSI}-1}(x)=\sum_{y=y_{1}}^{y_{2}} I_{\mathrm{LSI}-1}(x, y) \\ I_{\mathrm{LSI}-1}(y)=\sum_{x=x_{1}}^{x_{2}} I_{\mathrm{LSI}-1}(x, y)\end{array}\right.$

where $\left(x_{1}, y_{1}\right)$ and $\left(x_{2}, y_{2}\right)$ are the left-bottom and right-top coordinates of the target pixel area in the city light images, respectively. $\overline{I_{\mathrm{LSI}-1}(x)}$ and $\overline{I_{\mathrm{LSI}-1}(y)}$ are the average value of $I_{\mathrm{LSI}-1}(x)$ and $I_{\mathrm{LSI}-1}(y)$, respectively. $I_{\mathrm{LSI}-2}(x), I_{\mathrm{LSI}-2}(y), \overline{I_{\mathrm{LSI}-2}(x)}$, and $\overline{I_{\mathrm{LSI}-2}(y)}$ are the same as $I_{\mathrm{LSI}-1}(x), I_{\mathrm{LSI}-1}(y), \overline{I_{\mathrm{LSI}-1}(x)}$, and $\overline{I_{\mathrm{LSI}-1}(y)}$ except for the derivatives of the LSI- 2 image analyses. Using the 49 sets of city light image data and Eq. (2), we estimated the offset values. Figures $2 b$ and $c$ are the plots of the offset values to shift LSI-1 image in the X- and Y-pixel directions, respectively. From these plots, the offset values are empirically determined as the following equations,

$\left\{\begin{array}{l}X_{\text {lag }}=0.015 y_{0}-18 \\ Y_{\text {lag }}=-0.014 x_{0}+0.88\end{array}\right.$ 
where $x_{0}$ and $y_{0}$ are the representative $\mathrm{X}$ - and Y-pixel coordinates of the lightning emissions in the LSI-1 image. For example, if the centroid position of lightning emissions in a LSI-1 image is $\left(x_{0}, y_{0}\right)=(255,255)$, the offset values become $\left(X_{\text {lag }}, Y_{\text {lag }}\right)=(-14,-3)$ pixels. Based on Eq. (4), LSI-1 image data can be co-aligned with LSI-2 image data. Note that the linear dependence of $X_{\text {lag }}\left(Y_{\text {lag }}\right)$ on $x_{0}\left(y_{0}\right)$ indicates that an optical aberration exists in the LSI optical system.

As a final step, the appropriately scaled LSI-1 image subtraction from the LSI-2 image is performed. The lightning emission intensities in the LSI-1 image are first multiplied by a scaling factor $(1 / \alpha)$, then, the rescaled LSI-1 image is subtracted from the LSI- 2 image. This procedure corresponds to the subtraction of the suspected intensities of lightning emissions, which would be measured by LSI-2, from the LSI-2 image data. The following equation shows the subtraction procedure,

$I_{\text {sub }}(x, y)=I_{\mathrm{LSI}-2}(x, y)-\frac{I_{\mathrm{LSI}-1}(x, y)}{\alpha(x, y)}$

where $I_{\text {sub }}(x, y)$ is the subtracted image. In order to determine the coefficient $\alpha(x, y)$, we selected 210 pure lightning events, where the lightning emissions were detected by both LSI-1 and LSI-2 and no far-ultraviolet (FUV) emission was detected by PH1. Figure $3 \mathrm{a}$ is the pure lightning emission image detected at 04:50:21 UT on 14 October 2013. Note that the pixel size of these images is $80 \times 80$ trimmed from the original $512 \times 512$ size data. Using these image data, the intensity ratios of $I_{\mathrm{LSI}-1}(x, y) / I_{\mathrm{LSI}-2}(x, y)$ are calculated for the pixels where lightning emissions are detected in the LSI-2 image. Figure $3 \mathrm{~b}$ shows the variation in the intensity ratios plotted toward the LSI-2 intensities. In order to perform the fitting, we used four different functions, such as (1) the "curve fit" $\left[A \cdot \exp \left(B \cdot I_{\mathrm{LSI-}-2}\right)+C\right]$, (2) the "hyperbolic fit" $\left[1 /\left(A \cdot I_{\mathrm{LSI}-2}+B\right)\right],(3)$ the "geometric fit" $\left[A \cdot\left(I_{\mathrm{LSI}-2}\right)^{B}+C\right]$, and (4) the "log square fit" $\left\{A+B \cdot \log _{10}\left(I_{\mathrm{LSI}-2}\right)+C \cdot\left[\log _{10}\right.\right.$ $\left.\left.\left(I_{\text {LSI- } 2}\right)\right]^{2}\right\}$, where $A, B$, and $C$ are the parameters to be fitted. The blue, red, green, and purple solid lines denote the fitting results using the above four functions. The coefficient of determination $\left(R^{2}\right)$ is calculated to be 0.943 (curve fit), 0.951 (hyperbolic fit), 0.950 (geometric fit), and 0.948 (log square fit). Thus, it was found that the "hyperbolic fit" is the most suitable fitting function in this case. From the statistical analyses of 210 pure lightning events, the number of events where the $R^{2}$ value of "hyperbolic fit" becomes the highest compared with that of the other fitting functions, is the highest. Thus, we decided to use the following hyperbolic function to determine the coefficient $\alpha(x, y)$,

$\alpha(x, y)=\frac{1}{A+B \cdot I_{\mathrm{LSI}-2}(x, y)}$ where $A=2.46 \times 10^{-3}$, and $B=1.36 \times 10^{-3}$, respectively. The standard deviation $(\sigma)$ of $A$ and $B$ is $\sigma_{A}=1.64 \times 10^{-3}$, and $\sigma_{B}=1.36 \times 10^{-3}$, respectively.

Using the above three procedures, the image subtraction of the appropriately scaled LSI- 1 image from the LSI-2 image is performed. By checking the shape and distribution of the subtracted emissions and by comparing the subtracted emissions with the lightning emissions, the TLE occurrence is judged, especially for sprites.

\subsection{Peak Intensity Ratio and Occurrence Probabilities}

The absolute irradiance that $\mathrm{PH}$ receives can be calculated using the following equations,

$$
\left\{\begin{aligned}
I(\lambda)= & R(\lambda) \cdot \frac{C t s-C_{\text {offset }}}{\int R(\lambda) \cdot S(\lambda) \cdot G_{\text {Amp }} \cdot 10^{\left[7.0 \times \log _{10}(H V / 500)\right]} d \lambda} \\
& (\text { for PH } 1-3, \text { PH5, PH6) } \\
I(\lambda)= & R(\lambda) \cdot \frac{C t s-C_{\text {offset }}}{\int R(\lambda) \cdot S(\lambda) \cdot G_{\text {Amp }} d \lambda} \\
& (\text { for PH } 4)
\end{aligned}\right.
$$

where $I(\lambda)$ is the absolute irradiance at the wavelength $\lambda$ in the unit of $\mathrm{W} \mathrm{m}^{-2}, R(\lambda)$ is the spectral curve of the source emission in arbitrary units, $C t s$ is the output digital counts, $C_{\text {offset }}$ is the offset counts, $S(\lambda)$ is the instrumental sensitivity, $G_{\text {Amp }}$ is the gain of the amplifier, and $H V$ is the highvoltage value supplied to the photomultiplier tube (Adachi et al. 2013, 2016). Before the JEM-GLIMS launch we carried out the calibration experiment and measured the absolute instrumental sensitivity of each PH channel, as shown in Fig. 4. Note that the sensitivity profiles at $H V=500 \mathrm{~V}$ and $G_{\mathrm{Amp}}=1$ are plotted in this figure.

In order to judge the occurrence of TLEs, the detection of FUV emissions by PH1 is first checked because the existence of FUV emissions strongly supports the occurrence of TLEs. Chang et al. (2010) theoretically estimated the FUV intensities of lightning discharges detected by the ISUAL spectrophotometer (SP), and the estimated photon flux is $1.0 \times 10^{-11}$ photons $\mathrm{cm}^{-2}$. By converting the observation geometry of ISUAL into that of JEM-GLIMS and by assuming that the atmospheric transmittance does not change in this conversion, the expected FUV photon flux at JEMGLIMS becomes $\sim 5.6 \times 10^{-10}$ photons $\mathrm{cm}^{-2}$. If these photons are measured by PH1 operated with the maximum gain setting of $H V=1000 \mathrm{~V}$ and $G_{\text {Amp }}=10$, the output digital count becomes $C t s=5.0 \times 10^{-10}$, assuming that the time constant of the FUV emission is $1 \mathrm{~ms}$. Thus, we can conclude that it is impossible to detect the FUV emissions emitted by lightning discharges even at the ISS altitude and that the detection of FUV emissions by PH1 strongly supports the occurrence of TLEs because the atmospheric transmittance from the TLE altitude to the ISS is $\sim 1.0$. 

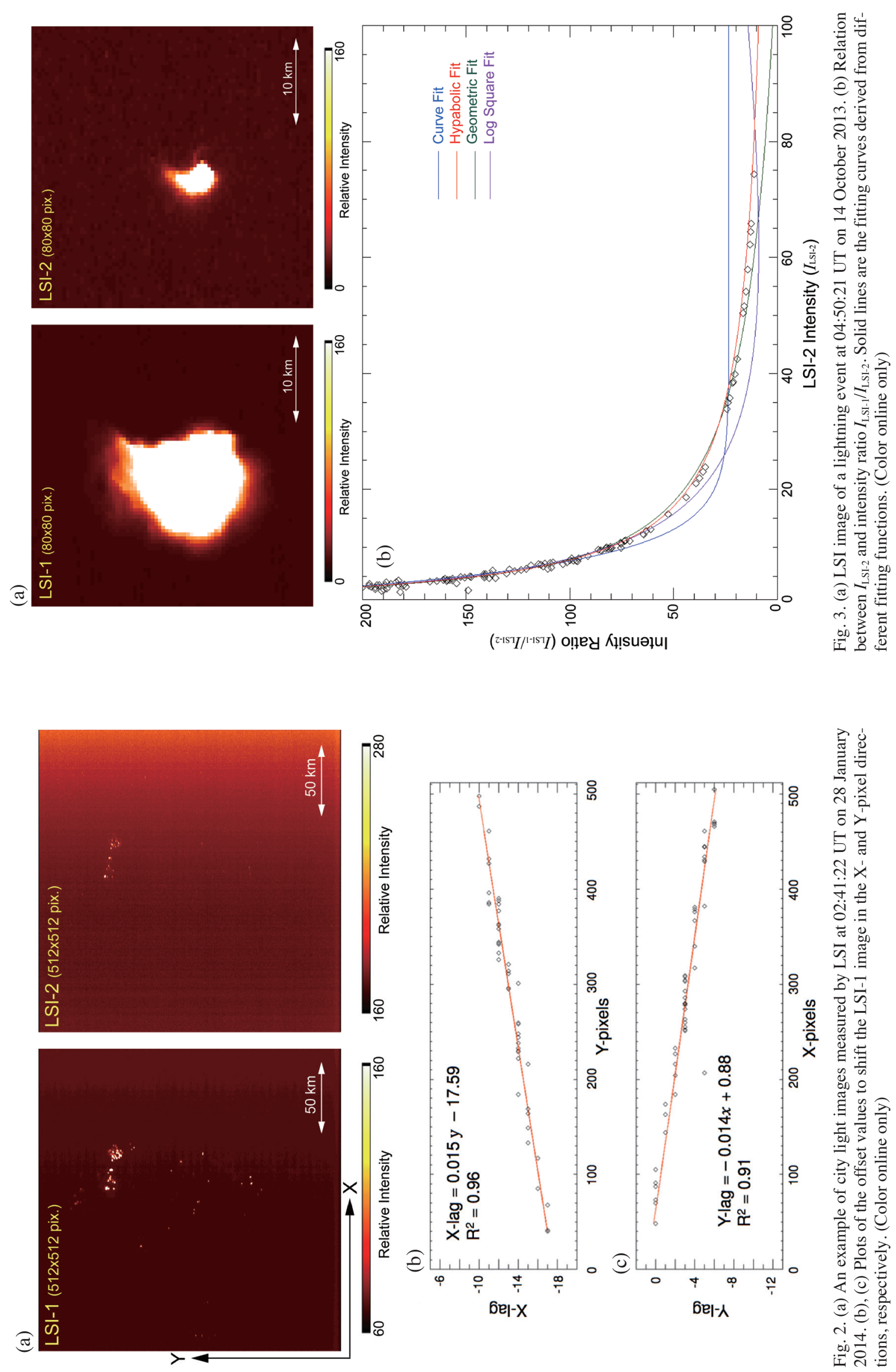

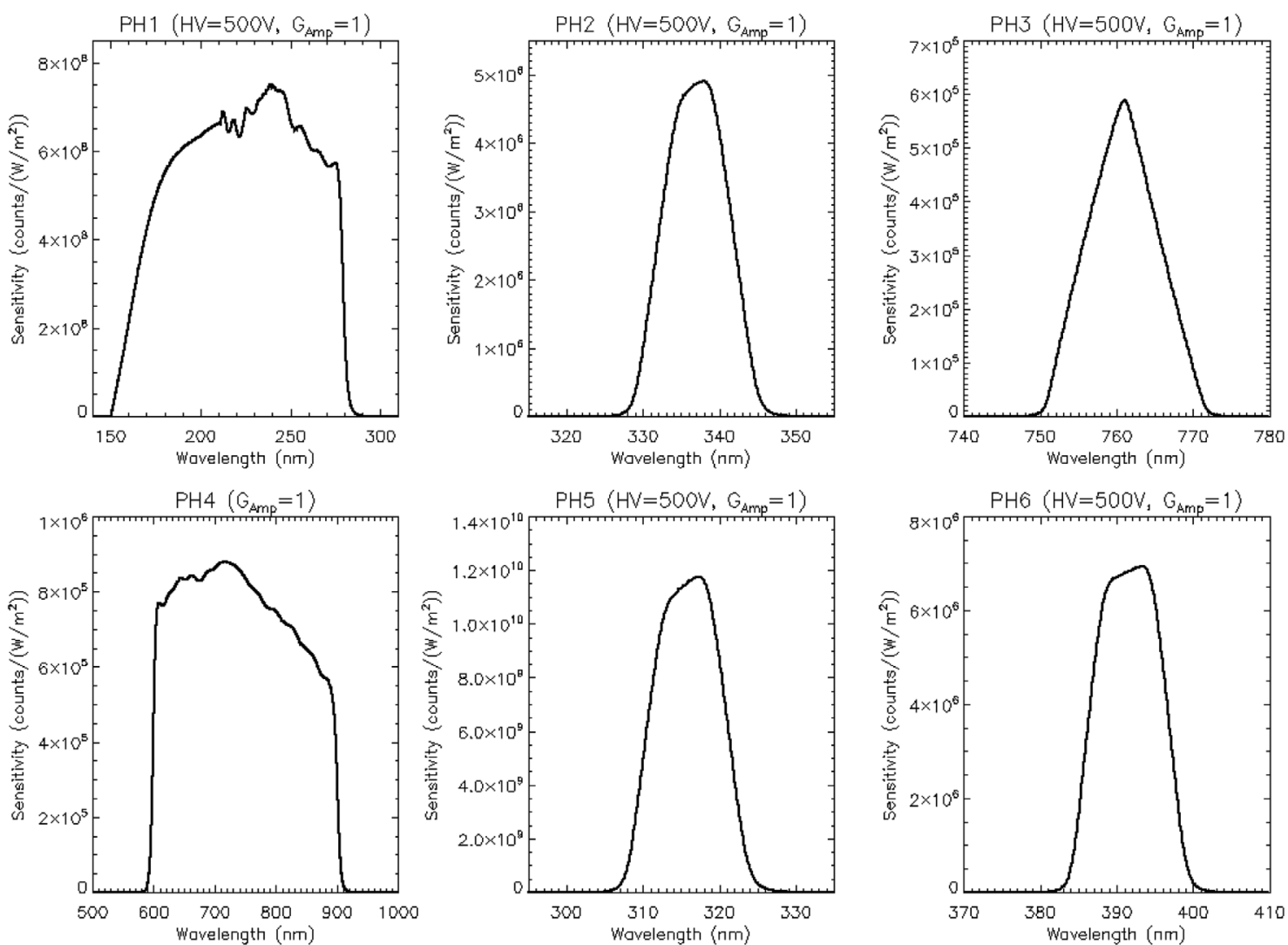

Fig. 4. The absolute sensitivity profile of each PH channel measured with the setting of the high voltage (HV) value of $500 \mathrm{~V}$ (except for PH4) and the amplifier gain $\left(G_{\text {Amp }}\right)$ of $\times 1$. Note that PH4 uses a Si photodiode as the photon detector and does not need the HV supply.

We also added one more criterion to judge the occurrence of TLEs in the PH data analyses. That is, the ratio between the peak intensity of PH2 $(332-342 \mathrm{~nm})$ and that of PH4 (red: $599-900 \mathrm{~nm}$ ) is another requirement. This criterion is derived from the comparison between the statistical analysis of ISUAL and JEM-GLIMS data. As a first step, we analyzed the 17835 pure lightning events, 145 spriteaccompanied lightning events, and 1502 elves-accompanied lightning events measured by ISUAL and estimated the peak intensities of the six SP channels. As ISUAL observed the lightning and TLEs in the limb direction, those peak intensities are converted into the intensities that would be observed with the JEM-GLIMS observation geometry, and the peak intensity ratios between the different SP channels are calculated. Consequently, it is found that the intensity ratio between SP2 (337 $\pm 4 \mathrm{~nm})$ and SP4 (red: $623-750 \mathrm{~nm})$ is a useful parameter for the criterion to distinguish the occurrence of lightning, sprites, and elves because the SP2/SP4 ratio rather than the ratios between other SP channels shows the clearest difference in magnitude in these events (Adachi et al. 2013, 2016).

As a next step, we analyzed PH data for the pure lightning events measured by JEM-GLIMS. We selected 202 pure lightning events, where no FUV emission was detected by $\mathrm{PH} 1$, and estimated the peak intensities of six $\mathrm{PH}$ channels. Figure 5 is a plot of PH light curve data for the lightning event detected at 04:50:21 UT on 14 October 2013, i.e., the lightning event shown in Fig. 3. Note that $t=0$ is the event trigger time at 04:50:21.01356 UT and that the LSI image shown in Fig. 3 was obtained at this trigger time. As no FUV emission was detected in PH1, this lightning event was not accompanied by TLEs. The peak intensity of each PH channel is PH2 $=1.1 \times 10^{-4}, \mathrm{PH} 3=6.7 \times 10^{-5}$, PH4 $=4.1 \times 10^{-3}, \mathrm{PH} 5=1.3 \times 10^{-5}$, and PH6 $=6.7 \times 10^{-5} \mathrm{~W} \mathrm{~m}^{-2}$. From these values, the absolute peak intensities normalized by the unit wavelength (i.e., $\mathrm{W} \mathrm{m}^{-2} \mathrm{~nm}^{-1}$ ) are calculated. The peak intensity ratio of $\mathrm{PH} 2 / \mathrm{PH} 4$ is then estimated to be 8.1. Similarly, we statistically estimated the $\mathrm{PH} 2 / \mathrm{PH} 4$ ratios for 202 pure lightning events.

From the SP2/SP4 ratios derived from the ISUAL data, the occurrence probabilities of lightning, sprites, and elves are estimated. The occurrence probability of $i$-th type (lightning, sprites, and elves) $P_{i}$ can be calculated using the following equation,

$P_{i}=\frac{N_{i}}{N_{\text {sprites }}+N_{\text {elves }}+N_{\text {halo }}+N_{\text {lightning }}}$ 
where $N_{i}$ is the occurrence number of $i$-th type, $N_{\text {sprites }}, N_{\text {elves }}$, $N_{\text {halo }}$, and $N_{\text {lightning }}$ are the occurrence number of sprites, elves, sprite halos, and pure lightning events. The occurrence probabilities of pure lightning, sprites, elves, and all TLE events are plotted in Fig. 6 with the black, red, green, and gray solid lines, respectively. In a similar manner, the occurrence probability of pure lightning events measured by JEM-GLIMS is calculated and plotted in Fig. 6 with the black dash-dot line. It was found that the occurrence probabilities of pure lightning events derived from ISUAL and JEM-GIMS data show a good consistency though there is a slight difference in the absolute values, which may be caused by the difficulty in correcting the atmospheric transmittance when the SP peak intensities are converted into the intensities as observed by JEM-GLIMS PH. Therefore, we concluded that the occurrence probabilities of sprites and elves derived from ISUAL data are applicable to JEM-GLIMS data. When the intensity ratio of SP2/SP4 (= PH2/PH4) is $1.44,2.95,6.45$, and 14.79 , the occurrence probability of TLEs is $20,40,60$, and $80 \%$, respectively (Adachi et al. 2013, 2016).

From above analyses, we defined the following two criteria to judge the occurrence of TLEs, (1) the detection of FUV emissions by PH1, and (2) the sufficiently high value of the $\mathrm{PH} 2 / \mathrm{PH} 4$ ratio.

\subsection{CMC Estimation}

One of the most important parameters for the assessment of sprite occurrence is the CMC or impulsive CMC (iCMC) values of the sprite-producing $\mathrm{CG}$ discharges because the intensity of the QE field, which triggers the conventional breakdown at the sprite altitude, is directly proportional to the CMC intensity of the CG discharges (Cummer and Inan 1997; Hu et al. 2002, 2007; Cummer 2003; Sato and Fukunishi 2003; Cummer and Lyons 2005; Li et al. 2008).

We used $1-100 \mathrm{~Hz}$ ELF magnetic field waveform data obtained by the Global ELF Observation Network (GEON) operated by Hokkaido University. Using the ELF data, CMC can be estimated from the following equation (Huang et al. 1999),

$H_{\phi}(f, \theta)=\frac{I \cdot d l(f)}{4 \pi R_{E} h_{0}} \sum_{n} \frac{2 n+1}{n(n+1)-\mathcal{V}(\mathcal{V}+1)} P_{n}^{1}(\cos \theta)$

where $H_{\phi}(f, \theta)$ and $I \cdot d l(f)$ are the power spectrum of the observed ELF waveform and the source lightning current moment change, respectively. $f, q, R_{E}, h_{0}, n$, and $v$ are the frequency, the angular distance between the source and the observer, the radius of the Earth, the reflection height of ELF waves, the mode number, and the complex propagation constant, respectively. $P_{n}^{1}$ is the associated Legendre polynomials for order $n$ and first degree. Assuming that the waveform of the source lightning current moment change has the shape of the exponential decay with a time constant $\tau_{0}$, the current moment spectrum is derived from the following equation,

$$
I \cdot d l(f)=\frac{I_{0} \cdot d l}{i \cdot 2 \pi f+1 / \tau_{0}}
$$

where $I_{0} \cdot d l$ is the peak current moment change. Using Eqs. (9) and (10), $I_{0} \cdot d l$ and $\tau_{0}$ can be estimated. Finally, CMC can be estimated from $\left(I_{0} \cdot d l\right) \cdot \tau_{0}=\left(I_{0} \cdot \tau_{0}\right) \cdot d l=Q \cdot d l$ (Huang et al. 1999; Füllekrug and Constable 2000; Sato and Fukunishi 2003).

From the Lissajous plot of ELF waveform data, we can estimate the bearing angle of the wave arrival at the observation site and estimate the propagation path of transient ELF waves (Sato and Fukunishi 2003; Sato et al. 2003). If the location of the source CG discharges exciting the transient ELF waves is provided, the polarity of the CG discharges can be determined by the polarity of the initial impulse of the transient ELF waves, and the propagation time of the waves can be calculated using the phase velocity of $v=0.8 c$ (Sato and Fukunishi 2003; Sato et al. 2003, 2008). These parameters can be used to judge the detected transient ELF waves are excited by the lightning discharges measured by JEM-GLIMS.

\section{SPRITE EVENT MEASURED BY JEM-GLIMS}

Using the TLE identification methods described in chapter 3, we confirmed that JEM-GLIMS detected sprite emissions in 42 out of 8357 lightning events. In this report, we introduce one of the sprite events in detail.

\subsection{Sprite Event Detected at 19:50:40 UT on 28 September 2013}

This sprite event was observed at 19:50:40.30580 UT on 28 September 2013, when the ISS was located at $\left(13.51^{\circ} \mathrm{E}, 5.32^{\circ} \mathrm{N}\right)$ and at $414.9 \mathrm{~km}$ altitude over Cameroon, Africa. Figure 7a is the infrared (IR) brightness temperature image measured by METEOSAT at 20:00 UT. Figure 7b is the expanded image of Fig. 7a, where the trajectory of the sub-satellite point (SSP) of the ISS and the SSP at the event are plotted by the dashed line and solid circle, respectively. In addition, the FOV of LSI is indicated by the red square. Within the LSI FOV, the thundercloud whose cloud top temperature was below $-50^{\circ} \mathrm{C}$ was located. Using the Mass Spectrometer Incoherent Scatter (MSISE-90) model (Hedin 1991; Picone et al. 2002), the altitude of the $-50^{\circ} \mathrm{C}$ temperature level is calculated to be $11.7 \mathrm{~km}$.

Figures $7 \mathrm{c}$ and $\mathrm{d}$ are four successive LSI-1 and LSI-2 images, respectively. Note that they are the expanded image trimmed from the original $512 \times 512$ size image and that the 

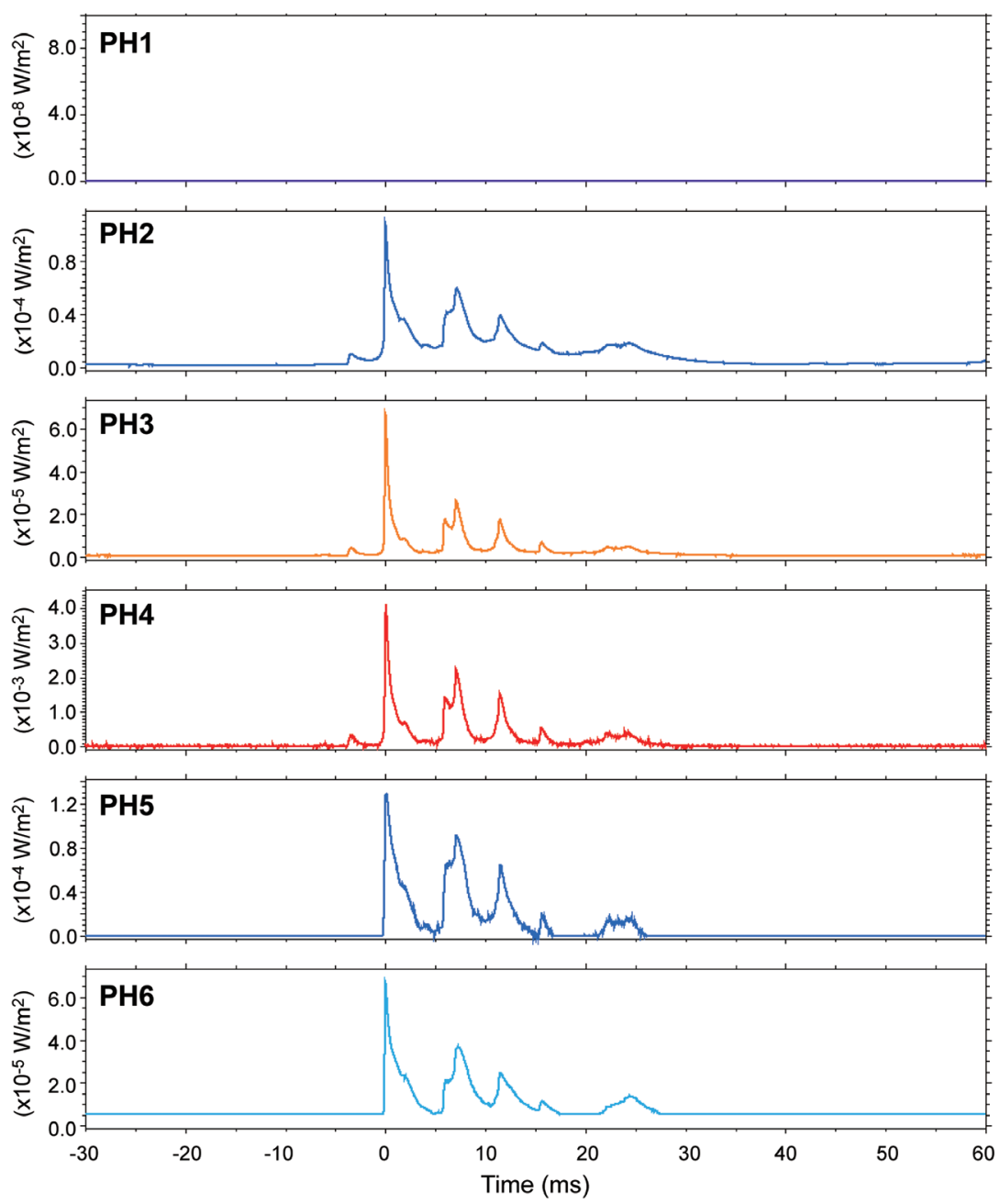

Fig. 5. Plot of the PH light curve data for the lightning event at 04:50:21 UT on 14 October 2013. The time of $t=0 \mathrm{~ms}$ corresponds to the trigger time at 04:50:21.01356 UT. (Color online only)

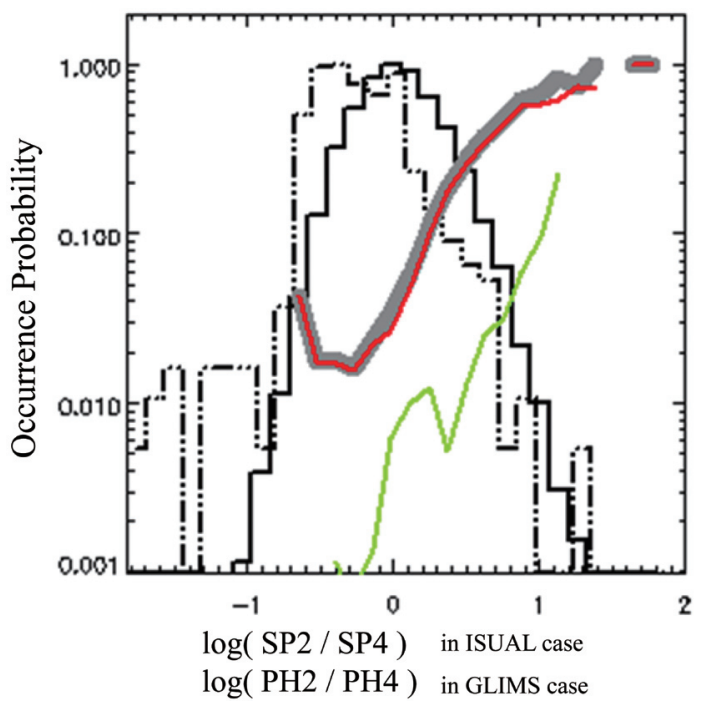

Fig. 6. Histogram of the occurrence probability of elves (red), sprites (green), and any types of TLEs (gray). The solid and dashed-dot lines are the occurrence probability of pure lightning events derived from ISUAL and GLIMS observations, respectively. (Color online only) 
(a)

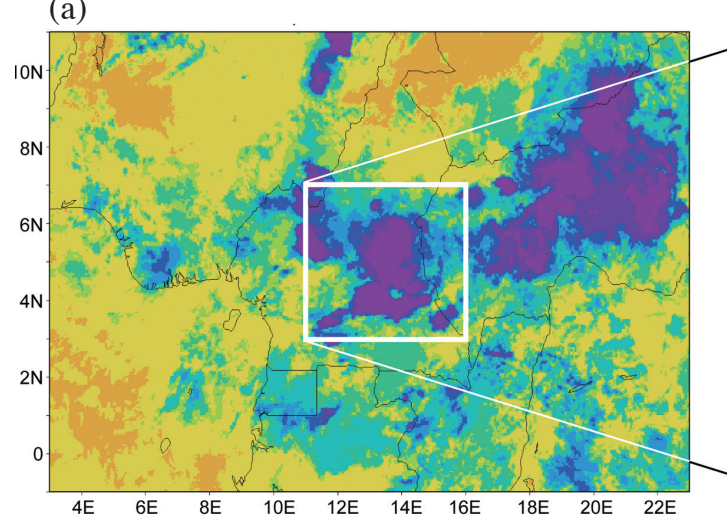

frame-1

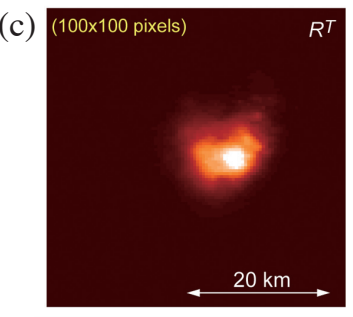

frame-2

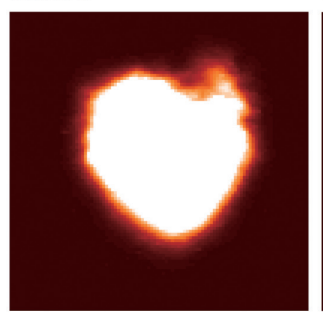

frame-3

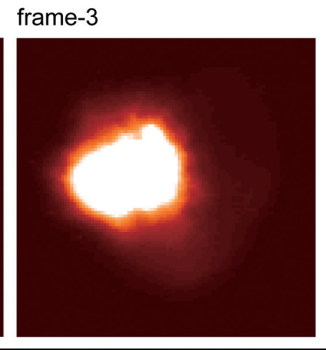

(d)

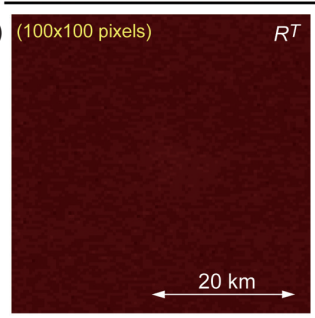

(b)
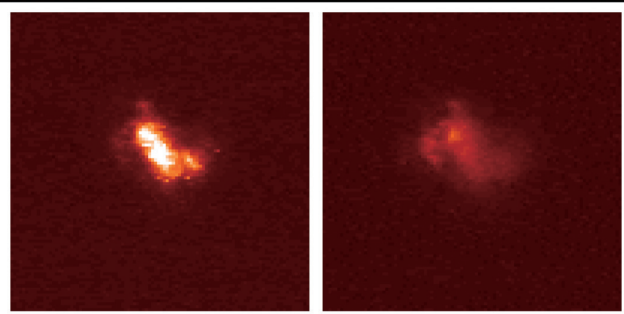

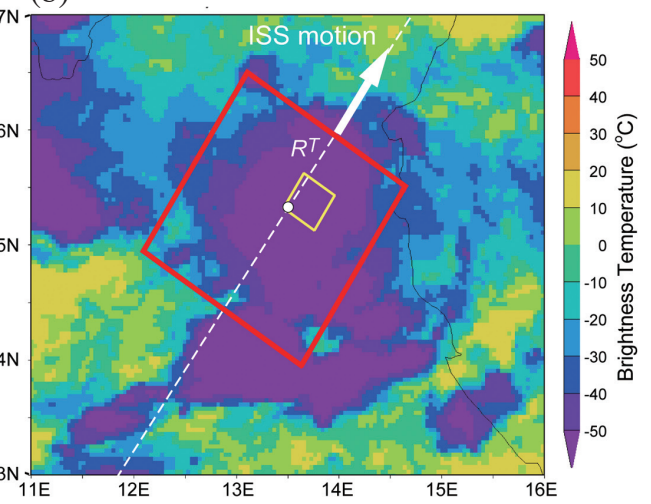

frame-4
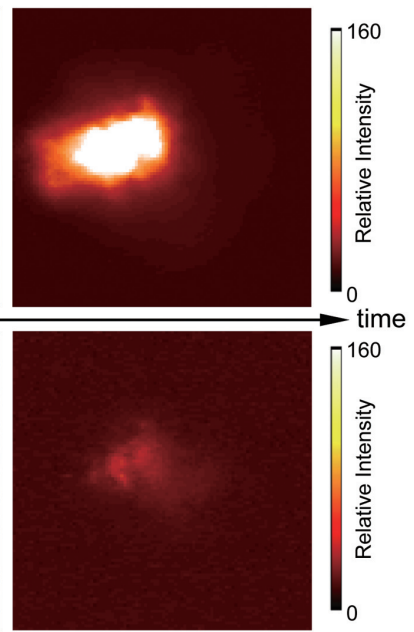

(e)

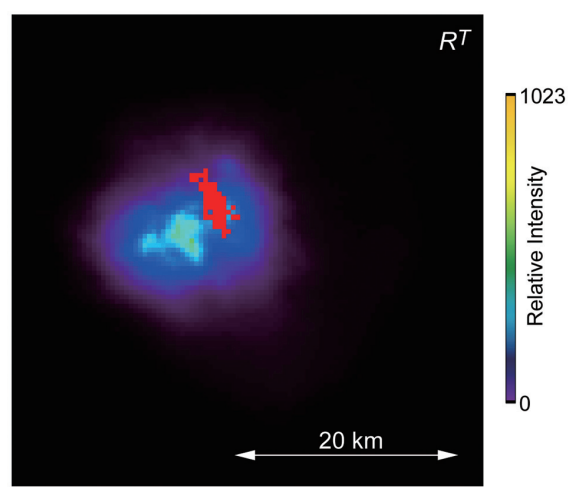

Fig. 7. (a), (b) Images of the IR brightness temperature measured by METEOSAT at 20:00 UT on 28 September 2013. The red and yellow squares in (b) are the FOV of the LSI at the detection time of the event and the area of the expanded LSI images in (c) - (e), respectively. (c), (d) Four consecutive images obtained by LSI-1 and LSI-2 at 19:50:40 UT on 28 September 2013, respectively. (e) Subtracted emissions (red spots) overplotted on the LSI-1 image.

image pixel size is $100 \times 100$. The trimmed image area is indicated by the yellow square in Fig. $7 \mathrm{~b}$, and " $R^{T}$ " shown in Figs. 7b, c, and d corresponds to a position in the topright corner of the images. As shown in Fig. 7c, the lightning emissions appeared near the center of the frame- 1 image and moved toward the left side edge from frame- 2 to frame- 4 . In contrast, LSI-2 detected the small-scale emissions at frame-2 as shown in Fig. 7d. However, the position of the emissions was almost the same in frame- 3 and frame- 4 . Using the frame-2 image data, subtraction of the appropriately scaled LSI-1 image from the LSI-2 image is performed, according to Eqs. (5) and (6). Figure 7e shows the image subtraction result. In this figure, the subtracted optical emissions whose intensities exceed the standard deviation by five times are plotted with the red color, and they are overplotted on LSI-1 image drawn by the rainbow color. It was found that the location of the subtracted emissions is clearly shifted from the brightest area of the lightning emissions. 
Figure $8 \mathrm{a}$ is the plot of the light curve data obtained by PH. Note that $\mathrm{t}=0 \mathrm{~ms}$ is the trigger time of this event at 19:50:40.30580 UT. It is clear that the FUV emission was detected by $\mathrm{PH} 1$ and that the optical emission whose time constant is $\sim 3$ ms was measured by the other PH channels. Due to the Mie scattering of the cloud particles, the light curve of the lightning emissions measured at the satellite altitude would be smoothed by $100-1000 \mu$ s compared with the original light curve (Light et al. 2001). Therefore, it is likely that the optical emissions measured by PH2 - PH6 originated mainly in the lightning emissions. In this event, the light curves of PH2 - PH5 are unfortunately saturated. So, these light curves are fitted by the PH6 light curve in order to estimate the peak intensities. The peak intensity of each PH channel is estimated to be $\mathrm{PH} 1=5.86 \times 10^{-7} \mathrm{~W} \mathrm{~m}^{-2}$, $\mathrm{PH} 2=2.64 \times 10^{-4} \mathrm{~W} \mathrm{~m}^{-2}, \mathrm{PH} 3=1.46 \times 10^{-4} \mathrm{~W} \mathrm{~m}^{-2}, \mathrm{PH} 4$ $=1.02 \times 10^{-2} \mathrm{~W} \mathrm{~m}^{-2}$, PH5 $=3.57 \times 10^{-5} \mathrm{~W} \mathrm{~m}^{-2}$, and PH6 $=$ $2.95 \times 10^{-4} \mathrm{~W} \mathrm{~m}^{-2}$, respectively. From these values, the absolute peak intensities normalized by the unit wavelength are calculated, and the ratio of each peak intensity to that of PH4 is estimated. Figure $8 \mathrm{~b}$ shows the intensity ratio for lightning events (black line) and this sprite event (red line). It was found that the $\mathrm{PH} 2 / \mathrm{PH} 4$ ratio is 23.3 , which implies that the TLE occurrence probability exceeds $80 \%$. Thus, the facts that the FUV emission was detected by $\mathrm{PH} 1$ and that the $\mathrm{PH} 2 / \mathrm{PH} 4$ ratio is 23.3 strongly support the occurrence of TLEs.

Figures $9 \mathrm{a}$ and $\mathrm{b}$ are the waveform plot of ELF data obtained at Syowa station $\left(39.51^{\circ} \mathrm{E}, 69.02^{\circ} \mathrm{S}\right)$, Antarctica and Esrange station $\left(21.10^{\circ} \mathrm{E}, 67.88^{\circ} \mathrm{N}\right)$, Sweden in the time period of 19:50:39.5 - 41.5 UT, respectively. Note that the magnetic field waveforms in the magnetic north-south $(\mathrm{H})$ and east-west (D) components are plotted in Fig. 9a, while those in the geographical north-south (NS) and east-west (EW) components are plotted in Fig. 9b. At Syowa station, the magnetic declination angle is $-48.489^{\circ}$ (westward from the geographical north). It was found that the transient ELF waves indicated by the vertical arrows were detected after the JEM-GLIMS event trigger time (dashed line). As the distance between the ISS SSP and Syowa station is $8.58 \mathrm{Mm}$, the ELF wave propagation time is calculated to be $35.8 \mathrm{~ms}$ assuming that the phase velocity of the waves is $V_{p h}=0.8 c$ (Füllekrug and Constable 2000; Sato and Fukunishi 2003). The transient ELF wave shown in Fig. 9a was observed at 19:50:40.340 UT at Syowa station. The expected source lightning occurrence time $\left(T_{\text {CG-SYO }}\right)$ is then 19:50:40.3042 UT. Assuming the lightning emissions altitude is $10 \mathrm{~km}$, the propagation time of light from the lightning to the ISS is $1.35 \mathrm{~ms}$, and the expected lightning discharge occurrence time $\left(T_{\text {GLIMS }}\right)$ is at 19:50:40.30445 UT. Thus, the difference between $T_{\mathrm{CG}-S Y O}$ and $T_{\mathrm{GLIMS}}$ is $\mid T_{\mathrm{CG}-\mathrm{SYO}}-T_{\mathrm{GLIMS}} \mathrm{I}=0.25 \mathrm{~ms}$. In a similar manner, the distance between the ISS SSP and Esrange station is $6.89 \mathrm{Mm}$, and the ELF wave propagation time is $28.7 \mathrm{~ms}$. As the ELF wave shown in Fig. 9b was observed at 19:50:40.333 UT, the expected source lightning occurrence time $\left(T_{\mathrm{CG}-\mathrm{ESR}}\right)$ is 19:50:40.3038 UT. Thus, the time difference of $\left|T_{\text {CG-ESR }}-T_{\text {GLIMS }}\right|$ is calculated to be 0.65 $\mathrm{ms}$. It was found that these time differences of 0.25 and 0.65 $\mathrm{ms}$ are less than the sampling period $(=1.25 \mathrm{~ms})$ of the ELF observation system. From the Lissajous plot of the ELF data, the bearing angle of the wave propagation path is calculated to be $336.3^{\circ}$ at Syowa station and $187.0^{\circ}$ at Esrange station. The estimated propagation paths are plotted in Fig. 9c. It was found that the cross-point of the two propagation paths is very close to the ISS SSP. The bearing angle from Syowa station to the SSP is $334.0^{\circ}$, while that from the Esrange station to the SSP is $187.9^{\circ}$. These angles are well comparable to the bearing angles of the propagation paths at Syowa and Esrange stations. Therefore, we concluded that the transient ELF waves observed at the two stations were excited by the lightning discharges measured by JEM-GLIMS. From the polarity of the initial impulse of the transient ELF waves, the lightning discharge is found to be $+\mathrm{CG}$ discharge. Using the Syowa and Esrange ELF data, the estimated CMC values are +2080 and $+1807 \mathrm{C} \mathrm{km}$, respectively, which is considered more than enough for sprite generation (Hu et al. 2002; Cummer and Lyons 2005).

From the results above, we identified that the subtracted optical structure shown in Fig. 7e corresponds to the sprite emissions.

\subsection{Horizontal Distribution of the Sprite Emission}

The lightning and sprites optical emissions measured by JEM-GLIMS do not always appear at the ISS nadir point. In order to precisely identify the horizontal distributions of sprites and clarify the spatial relation between the sprites and the sprite-producing lightning discharges, the occurrence locations of these emissions need to be corrected as observed from the point just above the sprite-producing lightning discharges. A schematic showing the geometry conversion method is presented in Fig. 10. In this geometry conversion, the altitude of lightning and sprite emissions is assumed to be 10 and $75 \mathrm{~km}$, respectively. The attitude vectors of the ISS and ISS position in the geocentric coordinate system are also used in the geometry conversion calculation. Note that the direction of the vector $\vec{z}$ is consistent with that of the FOV center of LSI and PH. Firstly, the optical emissions in the subtracted image are assumed to be located at $75 \mathrm{~km}$ altitude, and the longitude and latitude values of each pixel are estimated, i.e., $I m g_{\text {Sprite }}($ lon, lat) in Fig. 10. Secondly, in the same manner, the longitude and latitude values of each pixel in the LSI-1 image are calculated, i.e., $\operatorname{Img}_{\mathrm{CG}}(\mathrm{lon}$, lat) in Fig. 10. Each $I m g_{\text {Sprite }}($ lon, lat) pixel is over-plotted over the $I m g_{\mathrm{CG}}($ lon, lat) pixel as the longitude and latitude values of $I m g_{\text {Sprite }}$ become identical to those of $I m g_{\mathrm{CG}}$. From this procedure, we can correct the LSI observation geometry.

Figure 11a is same as Fig. 7e, which corresponds to the 
(a)
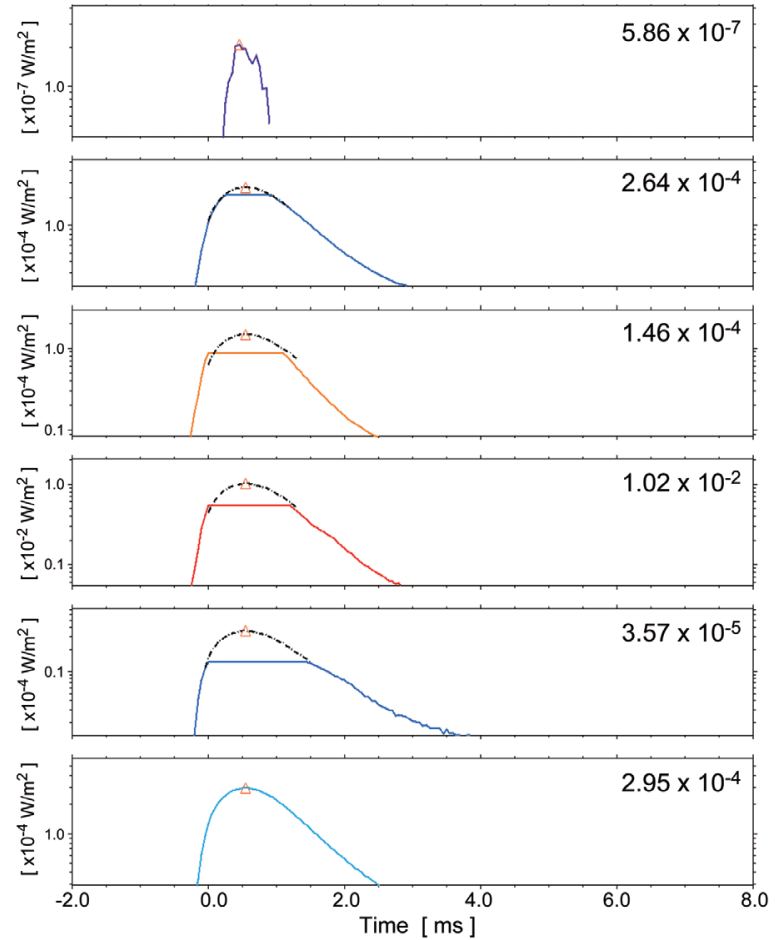

(b)

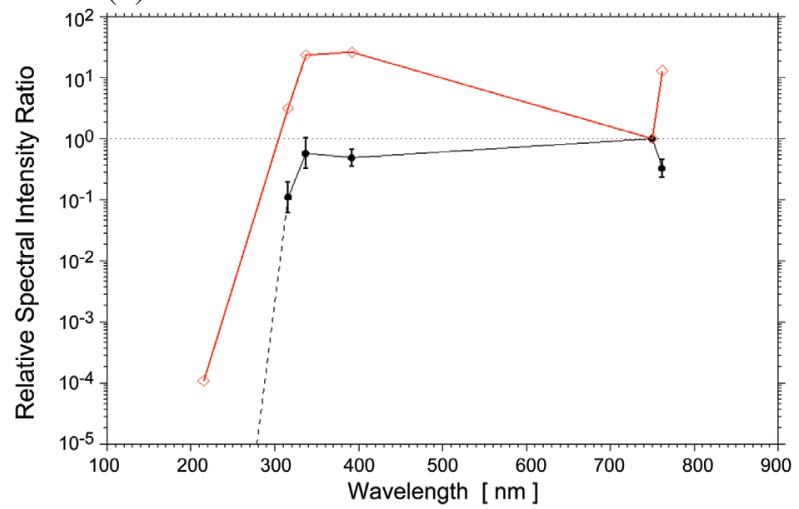

Fig. 8. (a) Plot of light curve data obtained by the PH at 19:50:40 UT on 28 September 2013. Dash-dotted lines at the PH2-PH5 plots are the fitting curves using the PH6 data. Solid triangle at each panel indicates the peak intensity. (b) Relative intensity ratio between the different PH channels. Black solid line is the intensity ratio for the typical lightning events measured by JEM-GLIMS, while the red line is the ratio for this sprite event (Color online only)

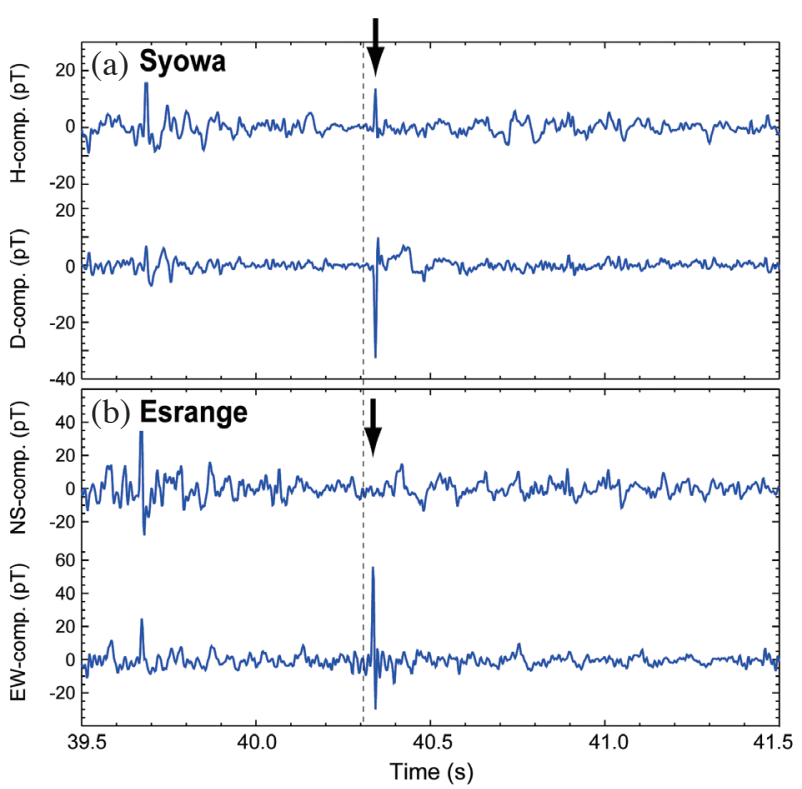

(c)

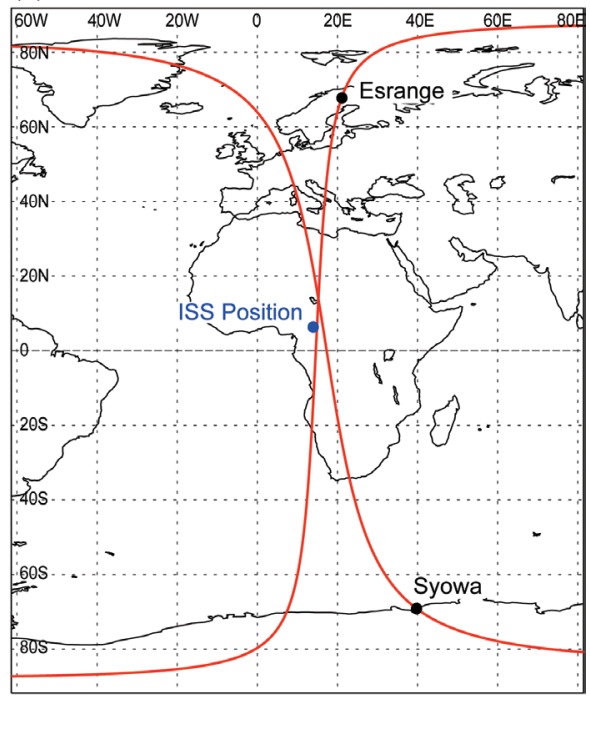

Fig. 9. (a) Plot of ELF waveform data obtained at Syowa station at 19:50:39.5-41.5 UT on 28 September 2013. (b) Same as (a) except for the data obtained at Esrange station. (c) Propagation paths of the transient ELF waves measured at Syowa and Esrange stations. (Color online only) 


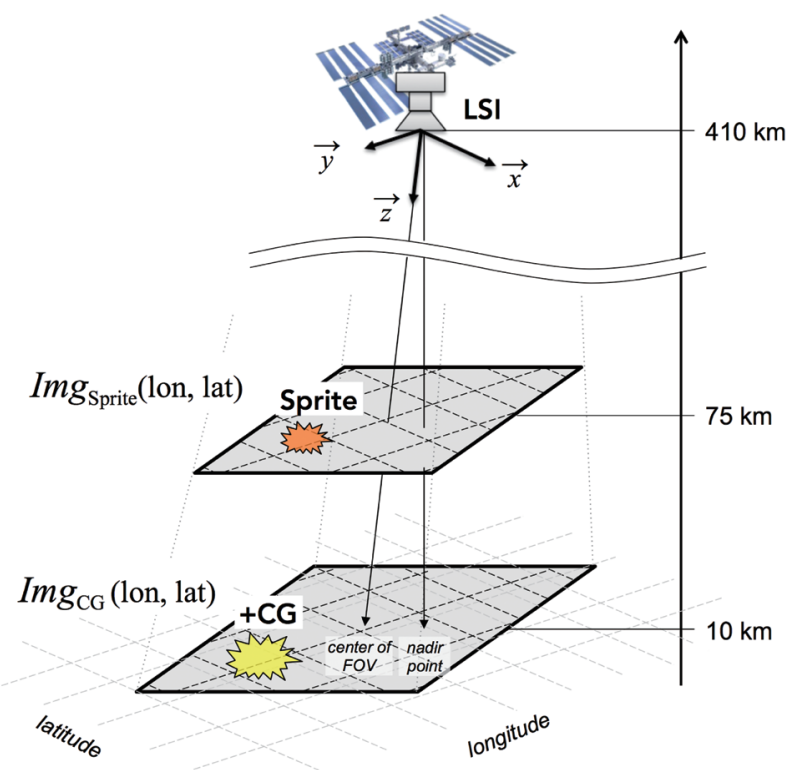

Fig. 10. Schematic showing the relation between $\operatorname{Img}_{\mathrm{Sprite}}\left(\right.$ lon, lat) and $\operatorname{Im} g_{\mathrm{CG}}($ lon, lat). (Color online only)

(a)

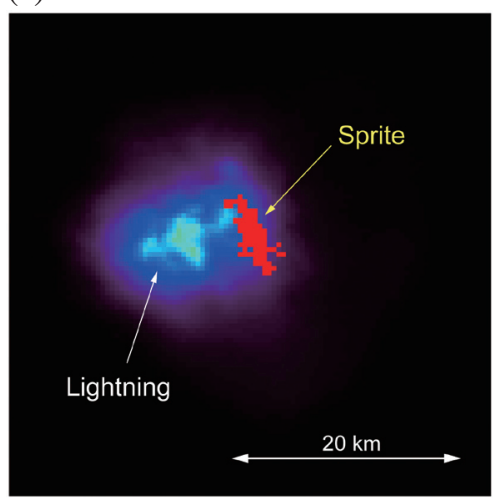

(b)

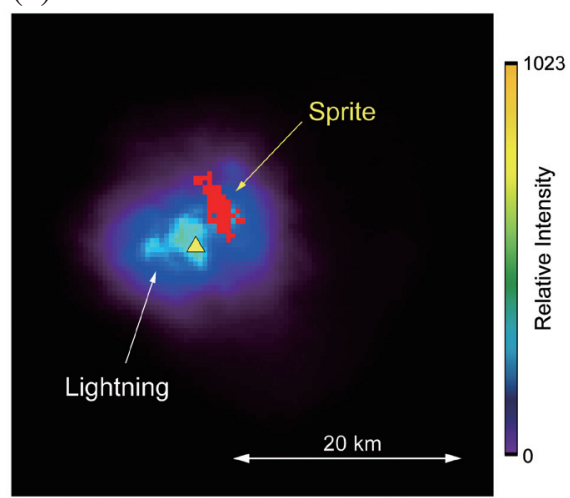

Fig. 11. (a) Sprite and sprite-producing lightning emissions before the geometry conversion, which is the same as Fig. 7e. (b) Geometry converted sprite and sprite-producing lightning emissions. The yellow triangle is the peak intensity location of the sprite-producing $+C G$ discharge.

image before the geometry conversion. In contrast, Fig. $11 \mathrm{~b}$ shows the geometry-converted image of the sprite emission and the sprite-producing $+\mathrm{CG}$ discharge emission. In this geometry-converted image, the sprite location moved slightly toward the ISS nadir point. The displacement of the sprite location from the location of the peak lightning emission intensity, denoted by the yellow triangle in Fig. 11b, is estimated to be $3.5 \mathrm{~km}$ on average. From the $\mathrm{PH}$ light curve data shown in Fig. 8a, the FUV emission from the sprite was found to be simultaneous with the parent +CG discharge, which implies that the sprite had a short delay time. Lu et al. (2013) pointed out that sprites having a short time delay from the parent lightning discharges $(<20 \mathrm{~ms})$ are typically centered within $30 \mathrm{~km}$ of the return stroke point of the parent lightning discharges. In the sprite event presented in this re- port, the horizontal displacement of the sprite emission from the peak lightning emission is $3.5 \mathrm{~km}$. Assuming that the location of the peak lightning emission corresponds to the return stroke point, the $3.5 \mathrm{~km}$ displacement is well consistent with the result of Lu et al. (2013). As shown in Fig. 11b, the sprite emission occurred just above the parent lightning emission, which may suggest that the center region of the charges neutralized by the +CG discharge in the thundercloud located just below the sprite emission.

As presented in section 2.3, JEM-GLIMS succeeded in detecting a total of 42 sprite events in the three-year observation period. We will analyze these sprite events further and statistically clarify the characteristics of the sprite horizontal distributions and the displacement of sprites from the parent lightning flash. 


\section{SUMMARY}

JEM-GLIMS was launched in July 2012 to realize the nadir lightning and TLE observations from the ISS. JEMGLIMS started continuous observations from November 2012 and finished the observations on August 2015. In this three-year period, JEM-GLIMS optical instruments successfully detected a total of 8357 lightning evens and 699 TLEs. From the detailed data analyses, 42 of 8357 lightning events are identified to be sprite events, which is $0.5 \%$ of the total lightning events.

As JEM-GLIMS uses the nadir observation technique, the JEM-GLIMS optical instruments have to simultaneously measure both incomparably intense lightning emissions and weak sprite emissions. For this reason, we needed to define the criteria to distinguish between these emissions and adopted combined data analytical methods: (1) the subtraction of the wideband LSI-1 image from the narrowband LSI-2 image, (2) calculation of the intensity ratio between different PH channels, and (3) estimation of the polarization and $\mathrm{CMC}$ of the suspected sprite-producing CG discharges. These data analytical techniques were precisely introduced in chapter 3 , and not presented in the previous literatures showing JEM-GLIMS results.

One sprite event identified using these methods was presented in detail. This sprite event was detected at 19:50:40.30580 UT on 28 September 2013 and occurred over Cameroon, Africa. The LSI image data show that the spatiotemporal changes in the lightning emissions detected by LSI-1 are different from those in the optical emission detected by LSI-2. From the image subtraction, it was found that clear optical structures are present in the subtracted image whose location is clearly shifted from the peak lightning emission location. In the PH data, the FUV emission is clearly detected by PH1, which strongly supports the occurrence of TLEs. We estimated the peak intensity ratio between different $\mathrm{PH}$ channels and confirmed that $\mathrm{PH} 2 / \mathrm{PH} 4$ is estimated to be 23.3. We also analyzed the ELF data obtained at Syowa and Esrange stations and found that the transient ELF waves are detected at both stations and confirmed that these waves were excited by the CG discharges detected by JEM-GLIMS. The polarity of the CG discharges is positive, and the CMC value derived from Syowa and Esrange ELF data is +2080 and $+1807 \mathrm{C} \mathrm{km}$, respectively, which is large enough to excite sprites. From all of these results, we judged that the optical emission in the subtracted image is the sprite emission. As the FUV emission detected by PH1 was simultaneous with the lightning-dominated emissions measured by PH2 - PH6, the detected sprite is confirmed to be a short-delayed sprite, which has the delay time shorter than $25 \mathrm{~ms}$ (Hu et al. 2007).

All of the sprite and sprite-producing lightning emissions measured by the JEM-GLIMS optical instruments did not occur just at the ISS nadir point. Therefore, these optical emissions must be replotted as observed from the location just above the sprite-producing lightning emission, that is, the geometry conversion is necessary. From the geometryconverted image, it is found that the sprite emission location shifted by $3.5 \mathrm{~km}$ from the peak lightning emission location. Lu et al. (2013) suggested that the horizontal displacement is less than $30 \mathrm{~km}$ for the sprites occurring within $20 \mathrm{~ms}$ after the occurrence of the sprite-producing lightning discharge. Thus, our result is fairly consistent with the result of $\mathrm{Lu}$ et al. (2013). As shown in Fig. 11b, the sprite emission location was over the parent $+\mathrm{CG}$ discharge optical emission. This fact may suggest that the center region of the charges neutralized by the $+\mathrm{CG}$ discharge occurred in the thundercloud located just below the sprite emission.

As presented in this report, the detailed horizontal sprite distributions and the relation between the sprite locations and the parent lightning locations are quantitatively revealed for the first time. We will analyze all sprite events detected by JEM-GLIMS further and statistically clarify the characteristics of the horizontal sprite distribution and the displacement of sprites from the parent lightning flash in future papers.

Acknowledgements This work was supported by JSPS KAKENHI Grant-in-Aid for Scientific Research (B) Number $16 \mathrm{H} 04055$ and 24340117, and MEXT KAKENHI Grantin-Aid for Specially Promoted Research Number 19002002.

\section{REFERENCES}

Adachi, T., Y. Hiraki, K. Yamamoto, Y. Takahashi, H. Fukunishi, R. R. Hsu, H. T. Su, A. B. Chen, S. B. Mende, H. U. Frey, and L. C. Lee, 2008: Electric fields and electron energies in sprites and temporal evolutions of lightning charge moment. J. Phys. D: Appl. Phys., 41, 234010, doi: 10.1088/0022-3727/41/23/234010. [Link]

Adachi, T., M. Sato, T. Ushio, A. Yamazaki, M. Suzuki, K. Masayuki, Y. Takahashi, U. Inan, I. Linscott, and Y. Hobara, 2013: Detection method of lightning and TLEs by JEM-GLIMS nadir observation. Abstract AE33A-0317 presented at 2013 Fall Meeting, AGU, San Francisco, Calif., 9-13 Dec. Available at http://abstractsearch.agu. org/meetings/2013/FM/AE33A-0317.html.

Adachi, T., M. Sato, T. Ushio, A. Yamazaki, M. Suzuki, M. Kikuchi, Y. Takahashi, U. S. Inan, I. Linscott, Y. Hobara, H. U. Frey, S. B. Mende, A. B. Chen, R. R. Hsu, and K. Kusunoki, 2016: Identifying the occurrence of lightning and transient luminous events by nadir spectrophotometric observation. J. Atmos. Sol.-Terr. Phys., 145, 85-97, doi: 10.1016/j.jastp.2016.04.010. [Link]

Blanc, E., T. Farges, R. Roche, D. Brebion, T. Hua, A. Labarthe, and V. Melnikov, 2004: Nadir observations of sprites from the International Space Station. J. Geophys. Res., 109, A02306, doi: 10.1029/2003JA009972. [Link] 
Blanc, E., T. Farges, A. Jehl, R. Binet, P. Hébert, F. Le Mer-Dachard, K. Ravel, and M. Sato, 2012: TARANIS MCP: A joint instrument for accurate monitoring of transient luminous event in the upper atmosphere. Proc. Int. Conf. Space Optics, ICSO-134, Corse, France, Oct. 9-12. Available at http://esaconferencebureau.com/custom/icso/2012/papers/FP ICSO-134.pdf.

Boeck, W., O. Vaughan Jr., R. Blakeslee, B. Vonnegut, and M. Brook, 1992: Lightning induced brightening in the airglow layer. Geophys. Res. Lett., 19, 99-102, doi: 10.1029/91GL03168. [Link]

Boeck, W., O. Vaughan Jr., R. Blakeslee, B. Vonnegut, and M. Brook, 1995: Observations of lightning in the stratosphere. J. Geophys. Res., 100, 1465-1475, doi: 10.1029/94JD02432. [Link]

Boeck, W., O. Vaughan, Jr., R. Blakeslee, B. Vonnegut, and M. Brook, 1998: The role of the space shuttle videotapes in the discovery of sprites, jets and elves. $J$. Atmos. Sol.-Terr. Phys., 60, 669-677, doi: 10.1016/ S1364-6826(98)00025-X. [Link]

Bucsela, E., J. Morrill, M. Heavner, C. Siefring, S. Berg, D. Hampton, D. Moudry, E. Wescott, and D. Sentman, 2003: $\mathrm{N}_{2}\left(\mathrm{~B}^{3} \Pi_{\mathrm{g}}\right)$ and $\mathrm{N}_{2}{ }^{+}\left(\mathrm{A}^{2} \Pi_{\mathrm{u}}\right)$ vibrational distributions observed in sprites. J. Atmos. Sol.-Terr. Phys., 65, 583-590, doi: 10.1016/S1364-6826(02)00316-4. [Link]

Chang, S. C., C. L. Kuo, L. J. Lee, A. B. Chen, H. T. Su, R. R. Hsu, H. U. Frey, S. B. Mende, Y. Takahashi, and L. C. Lee, 2010: ISUAL far-ultraviolet events, elves, and lightning current. J. Geophys. Res., 115, A00E46, doi: 10.1029/2009JA014861. [Link]

Cummer, S., 2003: Current moment in sprite-producing lightning. J. Atmos. Sol.-Terr. Phys., 65, 499-508, doi: 10.1016/S1364-6826(02)00318-8. [Link]

Cummer, S. and U. Inan, 1997: Measurement of charge transfer in sprite-producing lightning using ELF radio atmospherics. Geophys. Res. Lett., 24, 1731-1734, doi: 10.1029/97GL51791. [Link]

Cummer, S. and W. Lyons, 2005: Implications of lightning charge moment changes for sprite initiation. J. Geophys. Res., 110, A04304, doi: 10.1029/2004JA010812. [Link]

Ebert, U., C. Montijn, T. M. P. Briels, W. Hundsdorfer, B. Meulenbroek, A. Rocco, and E.M. van Veldhuizen, 2006: The multiscale nature of streamers. Plasma Sourc. Sci. Tech., 15, S118-S129, doi: 10.1088/09630252/15/2/S14. [Link]

Ebert, U., F. Brau, G. Derks, W. Hundsdorfer, C. Y. Kao, C. Li, A. Luque, B. Meulenbroek, S. Nijdam, and V. Ratushnaya, 2011: Multiple scales in streamer discharges, with an emphasis on moving boundary approximations. Nonlinearity, 24, C1-C26, doi: 10.1088/09517715/24/1/C01. [Link]

Franz, R., R. Nemzek, and J. Winckler, 1990: Television image of a large upward electrical discharge above a thunderstorm system. Science, 264, 48-51, doi: 10.1126/science. 249.4964.48. [Link]

Frey, H. U., S. B. Mende, S. A. Cummer, A. B. Chen, R. R. Hsu, H. T. Su, Y. S. Chang, T. Adachi, H. Fukunishi, and Y. Takahashi, 2005: Beta-type stepped leader of elve-producing lightning. Geophys. Res. Lett., 32 , L13824, doi: 10.1029/2005GL023080. [Link]

Fukunishi, H., Y. Takahashi, M. Kubota, K. Sakanoi, U. Inan, and W. Lyons, 1996: Elves: Lightning-induced transient luminous events in the lower ionosphere. Geophys. Res. Lett., 23, 2157-2160, doi: 10.1029/96GL01979. [Link]

Füllekrug, M. and S. Constable, 2000: Global triangulation of intense lightning discharges. Geophys. Res. Lett., 27, 333-336, doi: 10.1029/1999GL003684. [Link]

Gordillo-Vázquez, F. J., A. Luque, and M. Simek, 2011: Spectrum of sprite halos. J. Geophys. Res., 116, A09319, doi: 10.1029/2011JA016652. [Link]

Hedin, A. E., 1991: Extension of the MSIS thermosphere model into the middle and lower atmosphere. J. Geophys. Res., 96, 1159-1172, doi: 10.1029/90JA02125. [Link]

Hu, W., S. Cummer, W. Lyons, and T. Nelson, 2002: Lightning charge moment changes for the initiation of sprites. Geophys. Res. Lett., 29, 1279, doi: 10.1029/2001GL014593. [Link]

Hu, W., S. Cummer, and W. Lyons, 2007: Testing sprite initiation theory using lightning measurements and modeled electromagnetic fields. J. Geophys. Res., 112, D13115, doi: 10.1029/2006JD007939. [Link]

Huang, E., E. Williams, R. Boldi, S. Heckman, W. Lyons, M. Taylor, T. Nelson, and C. Wong, 1999: Criteria for sprites and elves based on Schumann resonance observations. J. Geophys. Res., 104, 16943-16964, doi: 10.1029/1999JD900139. [Link]

Inan, U., W. Sampson, and Y. Taranenko, 1996: Space-time structure of optical flashes and ionization changes produced by lightning-EMP. Geophys. Res. Lett., 23, 133136, doi: 10.1029/95GL03816. [Link]

Jehl, A., T. Farges, and E. Blanc, 2013: Color pictures of sprites from non-dedicated observation on board the International Space Station. J. Geophys. Res., 118, 454-461, doi: 10.1029/2012JA018144. [Link]

Kikuchi, M., M. Sato, A. Yamazaki, M. Suzuki, and T. Ushio, 2011: Development of science data handling unit (SHU) for Global Lightning and Sprite Measurements (GLIMS) onboard Japanese experiment module (JEM) of ISS. IEEJ Trans. Fundam. Mater., 131, 989-993, doi: 10.1541/ieejfms.131.989. [Link]

Kuo, C. L., R. R. Hsu, A. B. Chen, H. T. Su, L. C. Lee, S. B. Mende, H. U. Frey, H. Fukunishi, and Y. Takahashi, 2005: Electric fields and electron energies inferred from the ISUAL recorded sprites. Geophys. Res. Lett., 
32, L19103, doi: 10.1029/2005GL023389. [Link]

Kuo, C. L., A. B. Chen, Y. J. Lee, L. Y. Tsai, R. K. Chou, R. R. Hsu, H. T. Su, L. C. Lee, S. A. Cummer, H. U. Frey, S. B. Mende, Y. Takahashi, and H. Fukunishi, 2007: Modeling elves observed by FORMOSAT-2 satellite. J. Geophys. Res., 112, A11312, doi: 10.1029/2007JA012407. [Link]

Li, J., S. Cummer, W. Lyons, and T. Nelson, 2008: Coordinated analysis of delayed sprites with high-speed images and remote electromagnetic fields. J. Geophys. Res., 113, D20206, doi: 10.1029/2008JD010008. [Link]

Light, T. E., D. M. Suszcynsky, M. W. Kerkland, and A. R. Jacobson, 2001: Simulations of lightning optical waveforms as seen through clouds by satellites. J. Geophys. Res., 106, 17103-17114, doi: 10.1029/2001JD900051. [Link]

Liu, N. and V. Pasko, 2006: Effects of photoionization on similarity properties of streamers at various pressures in air. J. Phys. D: Appl. Phys., 39, 327-334, doi: 10.1088/0022-3727/39/2/013. [Link]

Lu, G., S. A. Cummer, J. Li, L. Zigoneanu, W. A. Lyons, M. A. Stanley, W. Rison, P. R. Krehbiel, H. E. Edens, R. J. Thomas, W. H. Beasley, S. A. Weiss, R. J. Blakeslee, E. C. Bruning, D. R. MacGorman, T. C. Meyer, K. Palivec, T. Ashcraft, and T. Samaras, 2013: Coordinated observations of sprites and in-cloud lightning flash structure. J. Geophys. Res., 118, 6607-6632, doi: 10.1002/jgrd.50459. [Link]

Luque, A. and U. Ebert, 2012: Density models for streamer discharges: Beyond cylindrical symmetry and homogeneous media. J. Comput. Phys., 231, 904-918, doi: 10.1016/j.jcp.2011.04.019. [Link]

Luque, A., U. Ebert, C. Montijn, and W. Hundsdorfer, 2007: Photoionization in negative streamers: Fast computations and two propagation modes. Appl. Phys. Lett., 90, 081501, doi: 10.1063/1.2435934. [Link]

Lyons, W., 1996: Sprite observations above the U.S. high plains in relation to their parent thunderstorm systems. J. Geophys. Res., 101, 29641-29652, doi: 10.1029/96JD01866. [Link]

Marshall, R., U. Inan, and V. Glukhov, 2010: Elves and associated electron density changes due to cloud-to-ground and in-cloud lightning discharges. J. Geophys. Res., 115, A00E17, doi: 10.1029/2009JA014469. [Link]

Mende, S. B., H. U. Frey, R. R. Hsu, H. T. Su, A. B. Chen, L. C. Lee, D. D. Sentman, Y. Takahashi, and H. Fukunishi, 2005: D region ionization by lightning-induced electromagnetic pulses.J. Geophys. Res., 110, A11312, doi: 10.1029/2005JA01 1064. [Link]

Morimoto, T., H. Kikuchi, M. Sato, M. Suzuki, A. Yamazaki, and T. Ushio, 2011: VHF lightning observations on JEM-GLIMS mission: Gradual approach to realize space-borne VHF broadband digital interferometer. IEEJ Trans. Fundam. Mater., 131, 977-982, doi: 10.1541/ieejfms.131.977. [Link]

Moudry, D., H. Stenbaek-Nielsen, D. Sentman, and E. Wescott, 2003: Imaging of elves, halos and sprite initiation at $1 \mathrm{~ms}$ time resolution. J. Atmos. Sol.-Terr. Phys., 65, 509-518, doi: 10.1016/S1364-6826(02)00323-1. [Link]

Nagano, I., S. Yagitani, K. Miyamura, and S. Makino, 2003: Full-wave analysis of elves created by lightning-generated electromagnetic pulses. J. Atmos. Sol.-Terr. Phys., 65, 615-625, doi: 10.1016/S1364-6826(02)00324-3. [Link]

Orville, R. and R. Henderson, 1984: Absolute spectral irradiance measurements of lightning from 375 to $880 \mathrm{~nm}$. J. Atmos. Sci., 41, 3180-3187, doi: 10.1175/1520-0469 (1984)041<3180:ASIMOL >2.0.CO;2. [Link]

Pasko, V., 2010: Recent advances in theory of transient luminous events. J. Geophys. Res., 115, A00E35, doi: 10.1029/2009JA014860. [Link]

Pasko, V., U. Inan, T. Bell, and Y. Taranenko, 1997: Sprites produced by quasi-electrostatic heating and ionization in the lower ionosphere. J. Geophys. Res., 102, 45294561, doi: 10.1029/96JA03528. [Link]

Pasko, V., U. Inan, and T. Bell, 1998: Spatial structure of sprites. Geophys. Res. Lett., 25, 2123-2126, doi: 10.1029/98GL01242. [Link]

Picone, J., A. Hedin, D. Drob, and A. Aikin, 2002: NRLMSISE-00 empirical model of the atmosphere: Statistical comparisons and scientific issues. J. Geophys. Res., 107, 1468, doi: 10.1029/2002JA009430. [Link]

Qin, J., S. Celestin, and V. Pasko, 2012: Formation of single and double-headed streamers in sprite-halo events. Geophys. Res. Lett., 39, L05810, doi: 10.1029/2012GL051088. [Link]

Qin, J., S. Celestin, and V. Pasko, 2013: Dependence of positive and negative sprite morphology on lightning characteristics and upper atmospheric ambient conditions. J. Geophys. Res., 118, 2623-2638, doi: 10.1029/2012JA017908. [Link]

Quick, M. G. and E. P. Krider, 2013: Optical power and energy radiated by natural lightning. J. Geophys. Res., 118, 1868-1879, doi: 10.1002/jgrd .50182. [Link]

Sato, M. and H. Fukunishi, 2003: Global sprite occurrence locations and rates derived from triangulation of transient Schumann resonance events. Geophys. Res. Lett., 30, doi: 10.1029/2003GL017291. [Link]

Sato, M., H. Fukunishi, M. Kikuchi, H. Yamagishi, and W. Lyons, 2003: Validation of sprite-inducing cloud-toground lightning based on ELF observations at Syowa station in Antarctica.J.Atmos. Sol.-Terr.Phys., 65, 607614, doi: 10.1016/S1364-6826(02)00327-9. [Link]

Sato, M., Y. Takahashi, A. Yoshida, and T. Adachi, 2008: Global distribution of intense lightning discharges and their seasonal variations. J. Phys. D: Appl. Phys., 41, doi: 10.1088/0022-3727/41/23/234011. [Link] 
Sato, M., Y. Takahashi, M. Kikuchi, M. Suzuki, A. Yamazaki, and T. Ushio, 2011a: Lightning and sprite imager (LSI) onboard JEM-GLIMS. IEEJ Trans. Fundam. Mater., 131, 994-999, doi: 10.1541/ieejfms.131.994. [Link]

Sato, M., Y. Takahashi, M. Suzuki, A. Yamazaki, and T. Ushio, 2011b: Six-channel spectrophotometers (PH) onboard JEM-GLIMS. IEEJ Trans. Fundam. Mater., 131, 1000-1005, doi: 10.1541/ieejfms.131.1000. [Link]

Sato, M., T. Ushio, T. Morimoto, M. Kikuchi, H. Kikuchi, T. Adachi, M. Suzuki, A. Yamazaki, Y. Takahashi, U. Inan, I. Linscott, R. Ishida, Y. Sakamoto, K. Yoshida, Y. Hobara, T. Sano, T. Abe, M. Nakamura, H. Oda, and Z.-I. Kawasaki, 2015: Overview and early results of the Global Lightning and Sprite Measurements mission. J. Geophys. Res. Atmos., 120, 3822-3851, doi: 10.1002/2014JD022428. [Link]

Sentman, D., E. Wescott, D. Osborne, D. Hampton, and M. Heavner, 1995: Preliminary results from the Sprites94 Aircraft Campaign: 1. Red sprites. Geophys. Res. Lett., 22, 1205-1208, doi: 10.1029/95GL00583. [Link]

Takahashi, Y., A. Yoshida, M. Sato, T. Adachi, S. Kondo, R. R. Hsu, H. T. Su, A. B. Chen, S. B. Mende,
H. U. Frey, and L. C. Lee, 2010: Absolute optical energy of sprites and its relationship to charge moment of parent lightning discharge based on measurement by ISUAL/AP. J. Geophys. Res., 115, A00E55, doi: 10.1029/2009JA014814. [Link]

Ushio, T., M. Sato, T. Morimoto, M. Suzuki, H. Kikuchi, A. Yamazaki, Y. Takahashi, Y. Hobara, U. Inan, I. Linscott, Y. Sakamoto, R. Ishida, M. Kikuchi, K. Yoshida, and Z. I. Kawasaki, 2011: The global lightning and sprite measurement (GLIMS) mission on the International Space Station: Concept and overview. IEEJ Trans. Fundam. Mater., 131, 971-976, doi: 10.1541/ ieejfms.131.971. [Link]

Yair, Y., P. Israelevich, A. D. Devir, M. Moalem, C. Price, J. H. Joseph, Z. Levin, B. Ziv, A. Sternlieb, and A. Teller, 2004: New observations of sprites from the space shuttle. J. Geophys. Res., 109, D15201, doi: 10.1029/2003JD004497. [Link]

Yair, Y., L. Rubanenko, K. Mezuman, G. Elhalel, M. Pariente, M. Glickman-Pariente, B. Ziv, Y. Takahashi, and T. Inoue, 2013: New color images of transient luminous events from dedicated observations on the International Space Station. J. Atmos. Sol.-Terr. Phys., 102, 140-147, doi: 10.1016/j.jastp.2013.05.004 . [Link] 